RESUMO

O objetivo deste ensaio é apresentar algumas das relações entre os conceitos de razão, consciência e ideologia. Nele serão destacadas relações entre ideologia liberal e razão, e entre o fetichismo e a (falsa) consciência; também serão associadas a razũo instrumental e a razão objetiva, tais como definidas por Horkheimer, respectivamente com o narcisismo e o amor objetal, conforme são compreendidos pela psicanálise. Por fim, serão discutidos três tipos de ideologia que se apresentam em nossos dias - a liberal, a tecnicista e a que se refere à mentira manifesta - e suas relações com necessidades psíquicas.

Descritores: razão; consciência; ideologia; Teoria Crítica da Sociedade; Psicanálise

\section{RAZÃO, \\ CONSCIÊNCIA E IDEOLOGIA: ALGUMAS NOTAS}

\author{
José Leon Crochík
}

( )

objetivo deste ensaio é pensar algumas das relações entre os conceitos de razão, de consciência e de ideologia. Quando a razão parece ter sido reduzida ao pensamento técnico; a consciência à adaptação aos preceitos vigentes e a ideologia a 'livres' formas de pensar, é importante retomar esses conceitos, considerando que refletem, em suas contradições e contraposições, uma sociedade de mal-estar contínuo e desagregador; mal-estar esse que as ilusões e diversões fornecidas pela cultura mal conseguem disfarçar. Assim, com o risco de repetir conceitos sabidos há muito tempo e sem a riqueza das formulações originais, deve-se voltar a refletir sobre eles, indicando uma relação entre indivíduo e sociedade que continua a viger em termos talvez mais problemáticos do que os de outrora; uma reflexão tendo em vista as exigências de adaptação do indivíduo a regras sociais que quase anulam as suas possibilidades de resistência, necessária a uma crítica social fundamentada em apreciação objetiva.

O texto será dividido em três partes. Na primeira, os conceitos de ideologia liberal e fetichismo

Docente do Instituto de Psicologia da USP e bolsista produtividade em pesquisa do CNPq. 
serão diferençados e relacionados com o conceito de falsa projeção, tal como definido por Horkheimer e Adorno (1947/1985) e com os dois tipos de razão descritos por Horkheimer (1946/1976): subjetiva e objetiva. Na segunda parte, serão propostas associações entre esses dois tipos de razão - subjetiva e objetiva - com os dois tipos de escolha de objeto sugeridos por Freud: narcisista e anaclítica. Por fim, na terceira parte, serão descritas três formas que a ideologia contemporânea assume - a liberal, a tecnicista e a fascista - e suas possíveis relações com necessidades psíquicas.

\section{Ideologia liberal e fetichismo: razão instrumental e razão objetiva}

Na Ideologia alemã, os ideólogos foram criticados por Marx e Engels (1847/1987) por quererem implantar o socialismo por meio da conscientização dos homens, desconsiderando o que produz a própria consciência: as condições concretas de produção; em $O$ capital (Marx, 1867/1984), a noção de fetiche assume também o papel de ideologia, mas, dessa feita, de forma distinta da liberal. Se a ideologia alemã apresentava um conteúdo a ser criticado por encobrir as suas condições de produção, o fetichismo envolve a inversão entre valor de uso e valor de troca: a mercadoria, que tem valor de uso, é vista como tendo inerente a si o valor de troca; os homens, que em suas relações estabelecem o valor de troca, são vistos como os que atribuem à mercadoria o valor de uso. Assim, no caso do fetichismo, a falsificação da percepção ocorre em relação à aparência da mercadoria e não em função das idéias que se tem acerca dela. Os homens determinariam o valor de uso, retirando a objetividade do produto, expressa por suas qualidades, e as relações entre as classes sociais que determinam o valor de troca seriam ocultas. Na ideologia liberal, a falsa consciência diz respeito à inversão entre as condições objetivas - aquelas necessárias à produção e reprodução da vida dos homens e da sociedade - e a consciência dos homens, representada pelas idéias que formulam sobre a sociedade existente; no tocante ao fetichismo, o elemento central é a percepção da aparência do que é produzido por essa sociedade; percepção essa que obsta o entendimento da estrutura social que medeia toda a produção social.

Assim, a crítica da ideologia alemã diz respeito à formulação de idéias sobre a realidade, enfatizando concepções sobre essa realidade, formuladas pelo pensamento; no fetichismo, a percepção da aparência social está em questão. Claro, a percepção (a consciên- 
cia) é fundamental para que a conceituação, por meio da razão, ocorra, mas a ideologia, referindo-se mais diretamente à percepção do imediato, é mais específica ao capitalismo dos monopólios - que pode prescindir do pensamento que vai além da aparência do que ao capitalismo concorrencial. Isso significa, tal como Horkheimer e Adorno (1956) entendem, que a ideologia se modifica historicamente em consonância com as modificações sociais ${ }^{1}$.

Horkheimer e Adorno (1947/1985) dizem que toda percepção é projeção, e que o conhecimento ocorre na relação entre sujeito e objeto. O homem projeta no objeto o que esse objeto seria; e, pela experiência, distingue o que é projetado e o que é objeto, que seria percebido, após o conhecimento, como algo distinto quer da projeção inicial, quer de seu isolamento. A falsa projeção (ou falsa consciência) resultaria na eliminação de um desses dois pólos. Quando há somente projeção, o objeto não é percebido; ele se torna unicamente o que o sujeito pretende que ele seja, e essa seria a base quer do idealismo, quer da paranóia. Quando se tenta controlar a projeção e negar o sujeito, deixando a ele o mero registro de dados, ocorre outro tipo de idealismo, de falsa consciência, que paradoxalmente nega o que o sujeito deposita no objeto.

Se, como diz Adorno (1969/1995), crítica do conhecimento é crítica da sociedade e vice-versa, as duas formas de ideologia e as duas formas de falsa projeção podem ser relacionadas: o idealismo alemão com o predomínio do sujeito sobre o objeto, e o fetichismo com a anulação do sujeito que produz valor. Claro, essa relação não é imediata e, assim, os elementos relacionados não são redutíveis uns aos outros. Contudo, a concepção de que há objetividade nos objetos - objetividade determinada pela forma como o homem se organiza para produzir e reproduzir as condições de sua vida, e que permite a própria objetividade do homem na constituição de sua subjetividade - é importante como crítica à ideologia. O sujeito se desenvolve a partir da objetividade; na ideologia, essa concepção é invertida.

A consciência depende de conhecimento, e este, segundo Kant (1781/1991), ocorre na experiência possibilitada pela relação entre os constituintes a priori do sujeito e o mundo fenomenal. Assim, há algo no objeto que o caracteriza que pode ser apropriado pelo pensamento. O conteúdo representaria o objeto, enquanto a forma representaria o sujeito. Como forma e conteúdo não se separam, a não ser quando a forma se torna o conteúdo, a projeção do sujeito suscitada e delimitada pelo objeto configuraria o conhecimento. O entendimento, a razão, seria um instrumento humano necessário à sobrevivência. Se a razão se torna um instrumento necessário e universal, não deixa, contudo, segundo Adorno (1969/ 
1995), de ser produto da abstração das relações entre os homens numa sociedade de trocas mercantis: "Na doutrina do sujeito transcendental, expressa-se fielmente a primazia das relações abstratamente racionais, desligadas dos indivíduos particulares e seus laços concretos, relações que têm seu modelo na troca. Se a estrutura dominante da sociedade reside na forma da troca, então a racionalidade desta constitui os homens; o que estes são para si mesmos, o que pretendem ser, é secundário.” (p. 186)

Isso não torna a razão menos necessária aos homens, mas indica que sua base, ou seja, a base de constituição dos sujeitos racionais é a troca. O equivalente da lógica formal, pelo qual todos os objetos podem ser comparados, espelha o equivalente do capital, que permite que todas as mercadorias expressem seu valor.

A razão, contudo, pode se expressar por mais de uma forma. Horkheimer (1946) delimita dois tipos de razão desenvolvidos na civilização ocidental: a razão subjetiva e a razão objetiva. A primeira seria a responsável pela sobrevivência, base da técnica, do conhecimento necessário para a sua produção; a segunda determinaria os valores universais, a verdade inerente à objetividade dos valores. Ao mostrar que ambas são limitadas, o autor indica a necessidade da superação desses limites, remetendo-se uma à outra. A razão subjetiva não vai além da reprodução da vida, dificultando ao homem a autoreflexão; a razão objetiva não considera a história, que revela a modificação das relações entre os homens. A razão subjetiva só pode pensar a ética formalmente; a razão objetiva não dá conta da construção de instrumentos necessários à autoconservação dos homens.

Além disso, no que diz respeito à razão objetiva, há outro problema; segundo Adorno (1969/1995), Kant insiste na razão individual, no imperativo categórico, possível com a unificação das inclinações individuais; Hegel, por sua vez, dá ênfase a questões políticas, no que têm de supraindividuais. Essa distinção, que se dirige para a separação entre ética e política, é entendida por Adorno (1969/1995) como cisão da consciência burguesa. Kant defende a autonomia individual; Hegel, a ação coletiva, política; uma deveria servir, segundo o frankfurtiano, de antídoto à outra. Não é possível uma ação política conseqüente calcada em um indivíduo, mas ela é nociva se não considera a consciência individual.

Nesse sentido, a ideologia liberal teria maior proximidade em relação à razão objetiva, buscaria e defenderia valores que poderiam transcender a adaptação, ao passo que o fetichismo se relacionaria mais com a percepção do imediato, do aparente, que é propícia à razão instrumental. Essa é uma suposição que não será desenvolvida neste ensaio, mas cujo aprofundamento nos levaria a entender melhor o cativeiro do sujeito, ao qual Adorno (1968/1996) se refere, e a exercer o primado do objeto, que defende como corretivo ao idealismo. 


\section{Razão e desejo: narcisismo e escolha anaclítica}

Com o surgimento da Psicanálise, as questões da consciência, da razão e da ideologia podem ser entendidas à luz de novos conceitos como os de inconsciente, pulsão, desejo. A compreensão das determinações inconscientes e da dinâmica pulsional na sua relação com os objetos permite uma forma distinta de entendimento da consciência dos sujeitos. $\mathrm{O}$ consciente e o pré-consciente, como um sistema, teriam uma lógica distinta do sistema inconsciente, pelo qual seriam afetados em sua constituição e funcionamento. Mas essa relação de lógicas distintas é camuflada por mecanismos psíquicos que defenderiam o indivíduo de sofrimentos. A falsidade da consciência seria produzida também devido aos desejos individuais.

Em seu texto Mal-estar na civilização, Freud (1930/1986) mostra a relação entre necessidades psíquicas e a introjeção de conteúdos ideacionais, que poderíamos entender como uma forma de ideologia. A necessidade de um pai protetor que defenda do sentimento do desamparo seria a base para a aceitação do conteúdo da religião. No estudo sobre a personalidade autoritária, Adorno, Frenkel-Brunswik, Levinson, and Sanford (1950) verificaram experimentalmente essa relação entre necessidades individuais e ideologia. Indivíduos que não superaram suas necessidades infantis seriam mais susceptíveis a ideologias fascistas do que os que conseguiram superá-las.

180 Estilos da Clínica, 2007, Vol. XII, nº 22, 176-195 
A consciência, para Freud, refere-se ao contato com o mundo externo e com o mundo psíquico. Pertence ao sistema perceptivo-consciente, que contém também o pré-consciente, no qual se alojam conteúdos próximos à consciência, que, com algum esforço, podemos recuperar. Esses conteúdos provêm de nossos contatos com objetos externos ou são expressões do inconsciente mediadas pela linguagem: antes de se tornarem conscientes, os conteúdos inconscientes tornam-se pré-conscientes. (Freud, 1923/1975)

A consciência se desenvolve com o surgimento do princípio da realidade, que é derivado do principio do prazer, e dos processos secundários, que são caracterizados pela lógica, pela linguagem. O princípio da realidade e os processos secundários surgem pelas experiências que temos com os objetos. De início, segundo Freud (1930/1986), não diferenciamos o que é externo do que é interno. Aos poucos separamos sensações agradáveis das sensações desagradáveis. As últimas são as derivadas das carências e das dores; as primeiras, da satisfação das carências e do alívio da dor. Uma primeira distinção surge delimitando nosso primitivo eu. Atribuímos, no começo, as atividades agradáveis a nós mesmos e as desagradáveis ao que não somos nós. Com a experiência, aprendemos que é o inverso que ocorre: as fontes das sensações desagradáveis, em geral, residem em nós mesmos e as agradáveis dependem de outro. Não obstante, Freud (1930/1986) ressalta que em alguns momentos da vida a inversão retorna, o que nos leva a pensar que a base da paranóia é latente para todos e pode a qualquer momento desenvolver-se; em contrapartida, o que a corrige ainda é a experiência, quando é possível a relação com um outro.

Disso, cabe ressaltar que, para Freud (1930/1986), todas as sensações que tivemos continuam a residir no inconsciente e podem mediar de tal forma nossas experiências que essas não cheguem a se concretizar, dado o predomínio do sujeito, nesse caso, o inconsciente, sobre o objeto. Além disso, nas primeiras experiências, um objeto imaginário que se refere a outro se forma; um objeto que não conseguimos saber o que ou quem é, e que buscamos ao longo de nossa vida sem jamais encontrar. Assim, a melancolia seria a marca de nossa vida ${ }^{2}$. Sob múltiplos disfarces, esse objeto imaginário medeia nossas relações e atividades. Dessa forma, a realização de desejos na psicanálise é impossível, posto que nunca chegamos a encontrar o referido objeto, mas as suas marcas mnemônicas sempre estão presentes, mesmo que alienadas e desconhecidas da consciência. Todas as experiências posteriores visam reaver esse objeto. $\mathrm{O}$ prazer relaciona-se a esse reencontro e o conhecimento - que diz respeito, sobretudo, à nossa diferenciação dos outros - ocorre na desilusão, no desencantamento que 
temos quando percebemos que o objeto desejado não é o que imaginávamos, nem poderia ser.

Para a psicanálise, somos alienados de nós mesmos, ainda que a denominada alienação psíquica também seja associada ao desconhecimento do mundo externo, representado pelo Princípio da Realidade. A não alienação refere-se ao conhecimento da distinção eu-mundo, que nunca é completa.

A relação com os objetos do mundo externo é, então, mediada pelas experiências do passado, mais precisamente pelos resíduos mnemônicos. O sistema perceptivo consciente não é caracterizado por marcas permanentes (Freud, 1920/1993a), ao contrário do que ocorre com os outros sistemas, cabe dizer, o inconsciente. São próprios dos conteúdos inconscientes o seu caráter atemporal e o seu desconhecimento do espaço. Freud (1920) atribui ao sistema consciente as noções de tempo e de espaço, categorias fundamentais da razão, segundo Kant (1781/1991). O pensamento e a razão pertencem à consciência e seus produtos, dessa forma, não deixam marcas. A reflexão (reflexo) não pertence ao inconsciente, esse pode fornecer matéria ao consciente, mas como a passagem do conteúdo inconsciente para o consciente é mediada pela linguagem, ele é transformado. Assim, o que é inconsciente nunca é efetivamente conhecido. Apesar dessa distinção, para a Psicanálise, o desejo é o pai do pensamento, ao que se deve acrescentar que se o pensamento pode expressar o desejo, pode também ocultá-lo. A realização do desejo deve contar com a astúcia do inconsciente para se disfarçar e, assim, o ego não ser penalizado ao ser descoberto pelo superego.

Se o desejo se relaciona com o Princípio do Prazer, este último, segundo Freud (1930/1986), expressase de duas formas: a busca do prazer e o combate ao sofrimento. A primeira meta só pode ser alcançada pelo amor, pela entrega ao objeto; ocorre que se essa forma de obter o prazer é a única satisfatória, ela é envolta em perigos, uma vez que o objeto de amor pode se recusar a nós ou, então, podemos perdê-lo, mas, como insiste Freud, é a barreira mais poderosa ao narcisismo - definido por Adorno (1955/1991) como a renúncia à consciência. As outras modalidades direcionadas a evitar o desprazer não convulsionam nosso ser e nem nos fazem esquecer-nos de nós mesmos ${ }^{3}$; são várias essas modalidades: as drogas, o isolamento, o controle das pulsões, o trabalho, a sublimação. O trabalho, quando livremente escolhido, e o pensamento científico, por combaterem as fontes de sofrimento, têm a vantagem de nos fixar na realidade.

$\mathrm{O}$ pensamento poderia evitar $\mathrm{O}$ desprazer ao ser adaptativo, enfrentar as fontes que nos geram sofrimento, e estaria claramente relacionado à autoconservação, mas isso só permite uma felicidade tênue. Conforme Adorno (1955/1991) já indicou, a obra de Freud é ao mesmo tempo promissora, pela denúncia aos adereços burgueses associados às pulsões, e conformista, no quanto pede pela contenção dessas pulsões. Assim é que em Mal-estar na civilização, Freud 
(1930/1986) diz que devemos agir no que se refere às diversas formas de busca da felicidade - em conformidade com o conselho dos negociantes: 'não depositar todos os ovos numa mesma cesta'. Não raro, contudo, com essas alternativas, abandona-se a busca do amor.

Parece não haver problemas em aceitar a idéia de que o desejo é o pai do pensamento, quando o que está em questão é a meta negativa da busca da felicidade: evitar o desprazer. Essa idéia é coerente com outra proposição freudiana: a de que trocamos parte de nossa felicidade (nesse caso dirigida à meta positiva), possível de ser alcançada com a libertação plena das pulsões na ausência da civilização, pela segurança que esta pode nos dar. Mas como o pensamento pode se relacionar com a meta positiva da felicidade?

Se no mundo pré-civilizado o homem podia ser livre, os objetos com os quais se relacionava não eram diferençados entre si, ou continham pouca diferenciação; as pulsões não inibidas em sua finalidade tinham livre vazão, mas sozinhas não poderiam delimitar o objeto amado. Para Freud (1921/1993b), o amor civilizado é síntese entre pulsões sexuais plenamente livres e pulsões inibidas em sua finalidade. Estas últimas são responsáveis pela particularização do objeto, pelo carinho, pela ternura. Mesmo o amor civilizado não se dissocia da tendência à destruição do objeto, contida no amor primitivo; como dizem Horkheimer e Adorno (1947/1985), o carinho é o tapa sublimado; o beijo, a mordida sublimada. No início da vida, o amor relacionado à fase oral contém o desejo de devorar o objeto amado - em geral, o seio materno. Esse desejo de incorporação está associado, na fantasia do pequeno infante, com a possibilidade de não depender de um objeto externo, relacionado à onipotência infantil, ou ao narcisismo ilimitado; em outras palavras, esse desejo está associado à negação da distinção eumundo. Mas não se trata de uma indistinção em que todos são iguais, tal como poderíamos pensar existir numa massa ou multidão, mas de uma na qual só o ego tem existência. Essa única distinção responsável por todas as outras não distinções também se expressa no processo civilizatório, segundo Horkheimer e Adorno (1947/1985), por uma única distinção: homem-natureza, os homens entre si e os objetos da natureza tornam-se presas de uma mesma lógica: a do sujeito. No desenvolvimento do indivíduo se reproduz a lógica da dominação social sobre os homens e sobre a natureza.

Assim, no caso do indivíduo, à real carência dos outros contrapõese o desejo da completa independência. Não dá para deixar de mencionar de passagem que esse desejo de completa auto-suficiência é continuamente suscitado pela formação burguesa; processo que nos dificulta a compreensão de que nosso eu é formado justamente por diversas identificações com os outros, dos quais não podemos prescindir, não só para a autoconservação, mas também para uma vida verdadeira. A identificação consiste em nos tornarmos outros; tomamos os outros como modelos. 
Claro, a identificação é mediada pelo desejo do que queremos e pensamos serem os outros, que não deixam, assim, de ter algo de idealizados, mas a experiência combate a idealização. De todo modo, o eu é composto por inúmeras identificações que ocorrem ao longo da vida, com destaque para as dos primeiros anos de vida.

A experiência com o objeto é fundamental para contrapor o desejo a esse objeto. Como esse último traz resistência ao desejo, permite uma melhor delimitação entre ambos, ou seja, a experiência com o objeto nos desilude, ele não é o que desejávamos que fosse, mas nisso reside algo da liberdade atual: não temos também de ser o que desejam de nós. Esse desejo pode ainda não ser desejo do objeto, mas o de nos reencontrarmos nele; pode ser um amor narcísico. $\mathrm{O}$ amor anaclítico ${ }^{4}$ é distinto, tem como base as identificações primeiras e a busca de outros objetos que possibilitem a revivescência dos amores objetais antigos. Temos assim dois tipos de amor: o narcísico e o anaclítico; este último diz respeito a um objeto distinto do eu. No amor narcísico sobrevive predominantemente o amor a si mesmo; no amor anaclitico, os objetos das primeiras identificações sobrepõem-se a esse eu primitivo.

Ainda que não seja de forma imediata, a relação entre o amor narcísico e a razão instrumental e a relação entre o amor anaclítico e a razão objetiva não podem ser desconsideradas. $\mathrm{Na}$ primeira relação, a necessidade de autoconservação é comum a ambos os elementos envolvidos; na segunda, a entrega ao objeto para além do eu é visível. Deve se considerar também que o narcisismo na criança é suscitado pelo narcisismo dos pais, que percebem no seu rebento a continuação de si mesmos. Se, de um lado, isso é importante, posto que o amor dos pais é fundamental para o desenvolvimento da criança, de outro lado, não devemos desconsiderar que essa análise se reporta à família burguesa: não há porque amarmos somente a nossos filhos; se houvesse a identificação com o que nomeamos humanidade e, dentro dela, com o que nos é digno de amor; pois, claro, não só o amor a todos não é possível, como não é desejável, já que, se não diferenciasse os objetos, a libido se expandiria para muitos outros objetos, combatendo o narcisismo. Não desconsideremos também que o narcisismo está associado à autoconservação e, assim, se ela estiver garantida, espera-se que o narcisismo dos pais diminua e que passem a amar os seus filhos como distintos de si. O amor narcisista busca o perpétuo reencontro consigo mesmo; o amor voltado ao objeto, o reencontro de uma relação perdida que se pôs no lugar dele.

A questão da autoconservação relaciona-se com a razão instrumental, e esta necessita do controle do objeto, que já é perceptível no desenvolvimento infantil. As perguntas iniciais de uma crian-

184 Estilos da Clínica, 2007, Vol. XII, nº 22, 176-195 
ça pequena visam o porquê das coisas serem assim e não de outro modo, buscam a origem do nascimento de si mesmo e dos outros. As perguntas delas remetem ao que é o objeto e caracterizam-se pela constante repetição dessas perguntas. Há também outro mecanismo das crianças que visa à repetição: a história e a música devem ser fiéis às originais. Um dos sentidos dados por Freud (1920/1993a) a esse mecanismo é o de lidar com o sofrimento. A criança que puxa o carretel com a linha e o afasta representa o controle que gostaria de ter de sua mãe que às vezes se afasta, às vezes se aproxima. A repetição dá a segurança de que o objeto perdido retornará e isso dependerá de nossa vontade. A compulsão à repetição, desse modo, está associada ao desespero de ter o controle sobre o objeto. Mas a repetição indica a Freud algo que vai além do princípio do prazer; algo que busca o eterno retorno. A vida é um desvio para a morte; a libido tenta prolongar esse desvio.

O pensamento calcado no tempo e no espaço, nas regras da lógica, busca o sempre igual, o como fazer, o como controlar. É produto da adaptação da espécie, e não deixa de se associar com desejos primitivos; por meio dos quais é possível esquecer as questões que nos angustiam. Freud (1920/1993a) distingue entre angústia, medo e terror: "Angústia designa certo estado de expectativa frente ao perigo e preparação para ele, ainda que se trate de um perigo desconhecido; o medo requer ainda um objeto determinado, em presença do qual é sentido; se chama terror, por sua vez, o estado em que se cai quando se corre um perigo sem estar preparado: destaca o fator da surpresa" (pp. 12-13)

A angústia, assim, é uma defesa contra o perigo, ainda que desconhecido, defende do terror, da surpresa. Se uma ameaça não claramente definida é intensa, a angústia a segue. Não é casual que nossa época seja a da angústia; mais propriamente, a nossa traz o disfarce da angústia: a frieza que tenta ocultá-la. A autoconservação, assim, seria mediada pela angústia, originada do medo, cujo objeto para nós é cada vez mais desconhecido: nada deve nos surpreender, e para isso é necessário saber como antever e controlar o perigo. Esse perigo não é somente externo, mas também interno: não temos consciência do que nos atemoriza. Assim, a reação ao mundo externo e nos tornarmos algo conhecido são formas de enfrentar perigos incertos.

Conforme foi dito, o pensamento que é dirigido à autoconservação não é livre da tarefa de combater o terror; a angústia, e a reação a ela, a frieza, estão na sua base. Tal como Horkheimer e Adorno (1947/1985) atribuem a Juliette, personagem de Sade, o gozo que ela demonstra em sua perfeita racionalidade, quando ten- 
ta humilhar os que fogem a essa racionalidade, também está presente: "Apesar de toda superioridade racional, Juliette conserva ainda uma superstição. Ela reconhece a ingenuidade do sacrilégio, mas acaba por tirar um prazer dele. Todo gozo, porém, deixa transparecer uma idolatria: ele é o abandono de si mesmo a uma outra coisa. A natureza não conhece propriamente o gozo: ela não o prolonga além do que é preciso para a satisfação da necessidade. Todo prazer é social, quer nas emoções não sublimadas quer nas sublimadas, e tem origem na alienação. Mesmo quando o gozo ignora a proibição que transgride, ele tem sempre por origem a civilização, a ordem fixa, a partir da qual aspira retornar à natureza, da qual aquela o protege. Os homens só sentem a magia do gozo quando o sonho, liberando-os da compulsão ao trabalho, da ligação do indivíduo a uma determinada função social e finalmente a um eu, leva-os de volta a um passado pré-histórico sem dominação e sem disciplina. É a nostalgia dos indivíduos presos na civilização, o 'desespero objetivo' daqueles que tiveram que se tornar em elementos da ordem social, que alimenta o amor pelos deuses e demônios; era para estes, enquanto natureza transfigurada, que eles se voltavam na adoração. O pensamento tem origem no processo de liberação dessa natureza terrível, que acabou por ser inteiramente dominada. O gozo é por assim dizer sua vingança." (pp. 100-101)

O terror da civilização que imita o terror da natureza leva ao gosto intelectual pela regressão. A raciona- lidade perfeita não independe dos desejos, que são disfarçadamente realizados por aquela; para tanto, deve esquecer o que a move. A famosa frase 'penso onde não sou e sou onde não penso', resposta à máxima de Descartes, só é verdadeira pelo esquecimento do que move o pensamento.

Retomando a questão da relação do pensamento com a busca da meta positiva do princípio do prazer, o amor ao objeto, podemos dizer que ela está presente na diferenciação desse objeto, algo de que participa também a percepção, ou projeção, como defendem Horkheimer e Adorno (1947/1985). Tal diferenciação leva o sujeito à busca de outro objeto que não o próprio eu, assim como à possibilidade de ser objeto para outros sujeitos: o amar e o ser amado se complementam, não esquecendo também que ambos se refletem. Ao podermos ser objetos do desejo de outros sujeitos, a nossa objetividade se expressa também pelas características que nos são atribuídas, mas que não necessariamente possuímos; contudo, isso nos dá a possibilidade de sermos mais do que objetos. Nisso se expressa o encantamento humano; a palavra, por exemplo, liberta o objeto nomeado quando indica para além dele, mas por intermédio dele. O que é criado pelos homens para a sua sobrevivência - a ciência, a técnica, a justiça - contém esse encanto da transformação dos objetos que nos transformam objetivamente. Se a magia era ilusória e precisava ser desencantada, com o desencanto da ciência, contudo, o sujeito perde a sua objetividade ao se converter em obje- 
to; nesse caso, um objeto que só satisfaz o desejo de manipulação, associado à onipotência infantil. O encanto que liberta está na relação com os objetos, na modificação possibilitada a eles e a nós; esse encanto se perdeu na ciência, na técnica e na justiça, uma vez que estas se tornaram meramente adaptativas, presas da racionalidade instrumental que, como vimos, tem sua base na troca mercantil. Assim, o amor ao objeto não pode prescindir da consciência da distinção entre esse amor e o sujeito, quer individual, quer coletivo; quando isso não ocorre, há o predomínio do sujeito que aniquila o que existe além dele, o que é base de toda ideologia.

Nessa distinção, a psicanálise pode auxiliar. A psicanálise, no entanto, como esclarecimento, contém a contradição; se o esclarecimento deve desencantar, a psicanálise também. Ela aponta para a ilusão de nossas paixões, deixando o mundo um deserto, tirando todo o sentido doado aos objetos, dirigindo-o aos sujeitos. Esse desencantamento, contudo, tal como o feito em relação aos mitos, coisifica a alma. A psicanálise, assim, não deixa de, ao desvelar o que se sobrepõe aos desejos infantis como disfarce, desencantar o sujeito, mas nesse desencanto a vida pode perder o seu sentido. A objetividade do sujeito - seus pensamentos, sentimentos, experiências - é reduzida à infância. Não que essa não tenha importância, mas, conforme defende Adorno (1955/1991), calcado em Nietzsche, o que surge depois não é menos verdadeiro do que a origem. Como dito antes, o encantamento pode se referir à magia, ao feitiço, e, nesse sentido, o esclarecimento é progressista quando desencanta, mas também pode significar o que atrai nossa paixão por aquilo que contém e nos afeta, por ser belo, quer no sentido histórico, quer natural, como o define Benjamin (1939/1989). O fim do mistério - o desencantamento é também o fim da busca de relações com os objetos. Segundo Horkheimer e Adorno (1947/1985), na crítica que fazem ao esclarecimento: 'Não deve haver nenhum mistério, mas tampouco o desejo de sua revelação' (p. 20). Dessa forma, a psicanálise, ao desvendar o mistério, pode também desencantar o desejo e auxiliar na criação da frieza. O desejo continuaria a existir, mas agora atenuado pela insensibilidade (A questão do encantamento voltará a ser tratada ao final deste texto.).

Se a angústia se refere a algo inespecífico, o pensamento não deixa de buscar a especificidade dos objetos. Mas aqui cabe uma distinção entre o pensamento que se estrutura no tempo, no espaço e na lógica e aquele que se volta para o que foi negado, quer individualmente quer coletivamente; aquele que não deixa de referir-se aos tabus (e aqui não se trata da razão objetiva, mas de uma que ao negar o existente revele as outras possibilidades até o momento não realizadas: uma razão histórica). Os tabus agem como resistência ao que é proibido, não permitindo compreendê-lo. O pensamento negativo deve contrapor-se aos tabus, revelando o seu anacronismo, ao evidenciar que se antes puderam ser necessários, hoje talvez não mais o sejam. 
Dessa forma, na relação entre razão e desejo, este último propicia a modificação do sujeito quando é associado com o que não é o sujeito; essa percepção, todavia, só é possível com uma razão que contemple a história das relações dos homens entre si e com a natureza, que compreenda a origem objetiva dos homens e considere a sua subjetividade como algo objetivo.

\section{Ideologia e necessidades psíquicas}

Se a consciência, de acordo com Freud (1920/1993a), serve de anteparo aos estímulos externos e recebe estímulos internos disfarçados, a ideologia, como falsa consciência, também disfarça o que é percebido do mundo externo ao indivíduo. Adorno (1955/ 1991) insiste que nem por isso racionalização e ideologia são o mesmo fenômeno, antes, articulam-se: "La racionalización privada, el autoengaño del espiritu subjetivo, no es lo mismo que la ideología, no es la falsedad del espiritu objetivo. No obstante, los mecanismos de defensa del individuo vuelven una y otra vez a buscar refuerzos en los de la sociedad, ya establecidos y acreditados muchas más veces ${ }^{5}$." (p. 171)

A ideologia que detém alguma racionalidade para ser criticada, segundo Horkheimer e Adorno (1956), só existiu no capitalismo concorrencial. Somente uma sociedade complexa traz a aparência socialmente necessária e o que ela oculta. Antes dessa forma de capitalismo e depois, a sociedade é suficientemente visível nas suas contradições.

A ideologia liberal era falsa e verdadeira ao mesmo tempo: verdadeira por seu conteúdo e por tentar pensar para além do existente, e falsa justamente pela negação do que impede a sua realização. As análises e propostas liberais continham a intenção de uma sociedade mais justa, mais livre, mas não de uma sociedade justa e livre. A ideologia atual, por sua vez, de uma forma geral, perdeu a sua racionalidade, constitui-se de mentiras manifestas, e assim sequer pode ser criticada. Horkheimer e Adorno (1956) defendem que é mais adequado dirigir-se às disposições individuais que ela visa atingir: "A crítica da ideologia totalitária não se reduz a refutar teses que não pretendem, absolutamente, ou que só pretendem como ficções do pensamento, possuir uma autonomia e uma consistência internas. Será preferível analisar a que configurações psicológicas querem se referir, para servirem-se delas; que disposições desejam incutir nos homens com suas especulações, que são uma coisa inteiramente distinta do que se apresenta nas declamações oficiais." (p. 192) 
As relações entre a psicologia e a política ganham visibilidade, tal como enuncia Marcuse (1955/1981) no prefácio a Eros e civilizacão, no início do século XX; a partir de então a análise do psíquico passa a remeter a problemas propriamente políticos, o que indica o empobrecimento do indivíduo. Na sociedade liberal, a individuação era importante para uma parcela da população, tendo em vista o estágio de desenvolvimento tecnológico, mas para a sociedade dos monopólios ela atrapalha (Horkheimer e Adorno, 1947/1985, p. 189) e, por isso, não é causal a pouca diferenciação existente entre $\mathrm{o}$ indivíduo e o que a sociedade pretende dele.

No que tange à consciência e à sua relação com o inconsciente, o trabalho de Adorno mostra o seu caráter histórico. Na mesma direção que o trecho acima citado, em seu trabalho sobre a música popular, em conjunto com Simpson (Adorno \& Simpson, 1941/1986), pergunta, dada a irracionalidade dos fenômenos de massa do século XX, se toda a distinção entre consciente e inconsciente permanece: "Na atual situação, talvez seja, por essas razões - que são apenas exemplos de fenômenos muito mais amplos da psicologia das massas -, apropriado perguntar até que ponto ainda se justifica toda a distinção psicanalítica entre o consciente e o inconsciente. As atuais reações das massas são bem pouco veladas da consciência. O paradoxo da situação é que é quase insuperavelmente difícil romper esse fino véu. Mesmo assim, a verdade não é mais subjetivamente tão inconsciente quanto se esperava que fosse.” (p. 146)

$\mathrm{Se}$, outrora, o que era considerado irracional devia ser reprimido, nos dias atuais, a irracionalidade é exaltada e o homem é aparentemente livre. Aparentemente, posto que se o que é irracional devia ser elaborado e não reprimido, a sua manifestação (aparentemente espontânea, mas já devidamente canalizada) contrapõese à razão e, assim, ao próprio homem. Se a razão é necessária para a constituição de uma sociedade de homens livres, ela não pode ser restringida às normas e regras sociais, sob a forma de racionalidade com respeito a fins, mas deve ser exercida pelos indivíduos; indivíduos que possam também fazer críticas racionais que transcendam esse tipo de racionalidade e tenham como alvo a verdadeira liberdade, a qual não pode prescindir da razão, e a felicidade, que só é verdadeira quando livre da opressão. Os indivíduos deixados sob o jugo de suas pulsões (e mesmo esse jugo é aparente, posto que o controle das pulsões é cada vez mais direto) mal tem condições de saber o que desejam, são emocionalmente infantis. A pouca distinção entre consciente e inconsciente, que dá margem à atuação irracional, é complementar à ideologia contemporânea; uma ideologia que, como dito, quase não se refere mais a conteúdos racionais que 
permitam a crítica, mas a desejos que devem ser suscitados nos indivíduos. A dominação atual da consciência ocorre também pela pseudoliberdade das pulsões.

Em seu texto Introducion a la sociologia, Adorno (1968/1996) argumenta que temos consciência dessa atuação irracional; haveria uma consciência duplicada: alienada e consciente da alienação. Nas palavras do autor: "Por trabajos realizados en el Instituto de Investigaciones Sociales, que lamentablemente no bemos podido desarrollar lo suficiente, tenemos algunos indicios de que se produce una curiosa dualidad. Por un lado, los individuos son obedientes a los mecanismos de personalización, tal como son ejercidos por la industria de la cultura (recuerdo los roles de Soraya y Beatriz); pero, por otro lado, si uno escarba solo un poco (y no necesita ningún 'cuestionario profundo' para ello; se puede comprobar muy fácilmente), se percata de que los individuos saben, en realidad, que lo importante no pasa por la princesa Beatriz. y la señora Soraya, o quien sea ${ }^{6} . "$ (p. 200)

Dessa forma, sabemos de nossas atuações irracionais e que a determinação de nossa vida transcende a responsabilidade individual, apesar da insistência com a qual a ideologia nos leva a pensar que tudo depende de decisões individuais. Resta a pergunta: por que procedemos dessa forma? Uma das possíveis respostas estaria na percepção da real impotência dos homens frente ao comando de seu destino. Como, de um lado, aprendemos que devemos ser autônomos para conduzir nossa vida e, por outro, percebemos condições sociais que impedem essa condução, queremos acreditar que o destino depende de nós; ao mesmo tempo, como o fracasso é inevitável, percebemos que não é isso que ocorre. Caberia pensar que, em uma sociedade livre, a decisão individual poderia existir para a maior parte de nossas ações, mas que a atual não permite a autonomia para além de limites restritos.

As disposições psíquicas que a propaganda fascista quer atingir no indivíduo dizem respeito à sua menoridade, expressa pela irracionalidade de seus atos, fruto do desespero gerado pela consciência da impotência individual; são caracterizadas pelo ressentimento dos que têm pouco a perder, pelo enfraquecimento do eu, a ausência da consciência moral, substituída pelos dispositivos sociais, pela identificação projetiva com o líder das massas. Se o ego se enfraquece, a consciência também, e torna-se presa fácil da ideologia carente de racionalidade. Paradoxalmente, se hoje a consciência é precária e alenta comportamentos irracionais, o pensamento formal é bastante incentivado e desenvolvido. Para essa constatação, basta estarmos atentos à força que o construtivismo, que tem como uma de suas bases a teoria de Piaget, tem na educação escolar brasileira. Menos do que um paradoxo, a racionalidade formal permite a expressão da irracionalidade, tal como é ilustrado pelo trecho citado de Horkheimer e Adorno (1947) acerca da personagem Juliette, criada por Sade. Isso é coerente com o que foi desenvolvido anteriormente: se o pensamento formal é externo em relação ao que é pensado e não imanente, o seu fortalecimento parece contrapor-se às 
significações do que foi esquecido, e não deixa de contribuir com uma das características da pessoa inclinada ao fascismo: a antiintracepção.

O pensamento formal, o pensamento técnico, a razão instrumental, em sua contradição, são propícios para a constituição de uma sociedade racional, com o custo de criar indivíduos irracionais (o que torna irracional a sociedade). A análise da obra de Sade, realizada por Horkheimer e Adorno (1947/1985), representam o burguês liberado de toda tutela, como queria Kant, cujas consequências, segundo os frankfurtianos, Sade e Nietzsche, entre outros, demonstraram. Apenas para retomarmos um aspecto já desenvolvido neste texto, essa razão não deixa de se associar com a crueldade, que pode, por sua vez, ser associada ao desejo de humilhar e inferiorizar aquele que se julga estar em dificuldades. Ao contrário da violência mais bruta, ela pode ser sutil e requintada, sem por isso perder a sua força devastadora. O desejo de destruição, de morte, está na sua base; e é importante usar o termo morte, pois essa, sobretudo com o fascismo, deixou de ter unicamente o seu sentido usual de fim da vida, adquirindo também o de aniquilação. Um conceito conciso para a crueldade seria o de resultado de formação reativa, que transforma o desejo de proximidade, que é negado, no de destruição do objeto, do qual se quer aproximar; esse conceito pode ser inferido do pensamento de Horkheimer e Adorno (1947/1985): “A compulsão à crueldade e à destruição tem origem no recalcamento orgânico da proximidade ao corpo, de maneira análoga ao surgimento do nojo, que teve origem, de acordo com a intuição genial de Freud, quando com a postura ereta e o afastamento da terra, o sentido do olfato, que atraía o animal humano para a fêmea menstruada, tornou-se objeto de um recalcamento orgânico.” (p. 217)

Essa compulsão à crueldade deve ser associada a outra frase de Horkheimer e Adorno (1947/1985), a de que, em nossa civilização, o prazer associou-se à crueldade e não ao amor.

O formalismo presente nas leis, nos valores (Ética), na democracia, expressa a dominação sob o modo de racionalidade e igualdade, numa sociedade irracional e desigual. Assim, as leis podem ser feitas para todos, desde que não atinjam os que têm poder. Mas a sociedade não se tornaria justa se aquela igualdade formal ocorresse, uma vez que essa igualdade formal não pode se relacionar com nenhum objeto particular; a relação entre o universal e o particular continuaria, por sua exterioridade, desconhecendo o particular. A igualdade que deveríamos almejar é a da expressão das diversas diferenças que nos tornam homens. $\mathrm{O}$ indivíduo não é mero exemplar da espécie: "A espécie talvez se tenha individuado por mutação para, logo, através de individuação, reproduzir-se em indivíduos, apoiandose no biologicamente singular. $\mathrm{O}$ homem é resultado, não Eidos; o conhecimento de Hegel e de Marx funda suas raízes no mais íntimo das chamadas questões da constituição." (Adorno, 1969/1995, p. 200) 
A individuação, assim, é necessária para a especificidade da humanidade; o indivíduo é produto, mas essencial para que a coletividade humana seja distinta das coletividades das abelhas e das formigas. O pensamento formal como técnica de autoconservação é importante para a constituição dessa coletividade; nem por isso, contudo, devemos considerá-lo, segundo Adorno (1968/1996), necessário no futuro. Em suas palavras: "A função cognoscente, sem a qual não haveria diferença nem unidade do sujeito, evadiu-se por sua vez. Ela consiste essencialmente naqueles formadores; na medida em que há conhecimento, este deve exercer-se de acordo com eles, mesmo ali onde se projeta para mais além deles. Eles definem o conceito de conhecimento. Não são no entanto absolutos, mas sim vieram a ser o que são da mesma forma que a função cognoscente como tal. Não é de todo impossível que poderiam perecer. Predicar seu caráter absoluto poria como absoluta a função $\operatorname{cog}$ noscitiva, absoluto o sujeito; relativizá-los revogaria dogmaticamente a função cognoscitiva.” (pp. 199-200)

A técnica, fruto do pensamento formal, segundo Marcuse (1964/ 1998), é quase uma ideologia, visto que nos dá formas para pensar o objeto antes de haver a experiência; como Horkheimer e Adorno (1947/ 1985) acentuam, a razão kantiana antecede a indústria cultural. Assim, a ideologia não se refere unicamente a conteúdos, mas também à forma de pensar.

Pelo que foi discutido neste texto, nos dias atuais é difícil dizer que existe uma única forma de a ideologia se manifestar; ela se expressa quer em sua forma liberal, quer como mentira manifesta, quer como racionalidade tecnológica. A exposição da existência dessas três formas de manifestação de ideologia não significa concessão ao relativismo, mas é coerente com a contradição presente no movimento histórico entre o que existia e o que passou a substituí-lo, isto é, as novas formas convivem com as antigas nesse movimento; dessa maneira, a ideologia liberal, própria do capitalismo concorrencial, e a tecnicista - ela mesma parte daquela - continuam a coexistir com a atual forma de ideologia; ao mesmo tempo, a tecnicista, por ser expressão do exagero da razão instrumental, não deixa de fortalecer a existência da ideologia que perpetua a irracionalidade social e a individual.

A ideologia liberal, por sua vez, traz alguma racionalidade no conteúdo expresso; a adesão à sua falsidade - inversão entre o real e a consciência - ocorre por reflexão insuficiente; na ideologia da racionalidade tecnológica, já como forma impede a consciência verdadeira, ou ao menos a crítica à falsa consciência; nela, o pensamento tende, em boa parte, a tomar a consciência, posto que só considera verdadeiro o que pode ser percebido pelo sistema que o constitui; e, por fim, a ideologia fascista a da mentira manifesta - busca a adesão por motivações diretamente psicológicas.

Como dito antes, a forma de pensamento presente na racionalidade tecnológica, que se afasta do objeto pensado e se desconhece como 
fruto da objetividade, permite que nos defendamos de ameaças do mundo externo; contudo, ao que parece, também serve de defesa contra ameaças psíquicas; serve como ideologia e como defesa psíquica, ainda que ambas não devam ser confundidas. Isso implica que esse pensar, ao dar as suas formas para a consciência, não permite, por um lado, a experiência com os objetos, pois, segundo Adorno (1969/1995), a forma não pode experimentar; por outro lado, entretanto, oculta e realiza desejos inconfessos, relacionados à ausência da experiência e a uma falsa onipotência. Essa forma que se repete e reafirma a todo o momento o sujeito em detrimento do objeto é o contrário do pensamento e atende necessidades narcísicas. Assim, o pensamento instrumental dirige-se ao narcisismo, a um estágio anterior à constituição de um eu, possibilitada pelas identificações a que se refere o amor anaclítico.

A ideologia como mentira manifesta suscita o cinismo, a ideologia da racionalidade técnica suscita o encantamento do desencantamento. Como Horkheimer e Adorno (1947/ 1985) observam, o esclarecimento visa ao desencantamento, mas a crítica ao animismo, tal como dito antes, converteu-se em coisificação das almas: o sujeito só se expressa como objeto que se repete sem ter consciência disso; como essa repetição está associada ao desejo da morte, da destruição, ela não deixa de ser encantada, tal como o mito o era. $\mathrm{O}$ encanto, por outro lado, refere-se à paixão pelo objeto, do qual não se consegue desvencilhar; ele dá vida ao objeto que, por sua vez, como diz Benjamin (1939) sobre a aura, nos retribui o olhar. Percebemos no objeto o que queremos que ele seja, mas também essa percepção é provocada pelo objeto que nos 'pede' para ser olhado; nessa relação, o homem se constitui. Se o encantamento que desvirtua o entendimento deve ser combatido, o mesmo não pode ocorrer com o encantamento do sujeito que o move em direção ao objeto; que se expressa nos sentimentos e nos pensamentos; que ao se aproximarem dos objetos permitem que estes os levem longe.

Já a ideologia que se expressa como mentira manifesta dirige-se diretamente ao que é desejado por aquele que se sente impotente e precisa ver confirmada a falsa onipotência como defesa. O narcisismo também é uma de suas bases: a divisão do mundo em fortes e fracos, a identificação com a força, o culto à saúde, que serve como defesa contra a angústia da morte.

Se o narcisismo é base psíquica dessas duas expressões de ideologia; e se, segundo Adorno (1955), ele implica a renúncia à consciência, a mentira manifesta dirige-se diretamente aos desejos e temores de um eu que se sabe frágil e tenta se fortalecer, e a ideologia da racionalidade tecnológica, à negação desses desejos.

Se a vida dirigida à autoconservação já poderia ser superada, mas não o é, as ideologias atuais fomentam a adaptação à sociedade existente, eliminando as possibilidades da consciência das contradições que nos levariam a lutar pela sua superação. Como é possível inferir do trabalho dos 
frankfurtianos, há um resíduo dessa consciência que ainda sobrevive, mas a ameaça ao eu é tão forte que ela continua imersa em sombras.

\section{Abstract}

REASON, CONSCIOUSNESS AND IDEOLOGY: SOME NOTES

The objective of this essay is to present some of the relations between the concepts of reason, consciousness and ideology. Relations between liberal ideology and reason, fetishism and (false) conscience will be detached; also the instrumental reason and the objective reason will be associated, such as defined for Horkheimer (data), respectively with narcissism and object love, as they are understood by psychoanalysis. Finally, this work discusses three types of ideology present in our days - the liberal one, the technicist and the one that refers to manifest lie - and its relations with psychic necessities.

Index terms: reason; consciousness; ideology; Critical Theory of Society; Psychoanalysis

\section{RESUMEN}

RAZÓN, CONCIENCLA Y IDEOLOGÍA: ALGUNAS NOTAS

El objetivo de este análisis es presentar algunas de las relaciones entre los conceptos de razón, conciencia y ideología. En él, las relaciones entre la ideología liberal, la razón, el fetichismo y la (falsa) conciencia serán discutidas; tamben son asociadas la razón instrumental e la razón objetiva, tales como definidas por Horkheimer (data), respectivamente con el narcisismo e con el amor objectal, conforme comprendidos pela psicoanálisis. Finalmente, son discutidos tres tipos de ideología que se presentan en nuestros dias - la liberal, la tecnicista y la que se relaciona con la mentira manifiesta - y sus relaciones con las necesidades psíquicas.

Palabras clave: razón; conciencia; ideología; Teoría crítica de la sociedad; psicoanálisis.

\section{REFERÊNCIAS BIBLIOGRÁFICAS}

Adorno, T. W. (1991). De la relación entre sociología y psicología. In T. W. Adorno, Actualidad de la filosofia. (J. L. A. Tamayo, trad., pp.135-204). Barcelona: Paidós Ibérica S.A. (Trabalho original publicado em 1955).
(1995). Sobre sujeito e objeto. In T.

W. Adorno. Palavras e sinais. (M. H. Ruschel, trad., pp. 181-201). Petrópolis, RJ: Vozes. (Trabalho original publicado em 1969).

(1996). Introducción a la sociologia.

(E. R. López, trad.). Barcelona: Editorial Gedisa. (Trabalho original publicado em 1968)

Adorno, T.W., Frenkel-Brunswik, E., Levinson, D. J. \& Sanford, R. N. (1950). The Authoritarian Personality. New York, NY: Harper and Row.

Adorno, T.W. \& Simpson, G. (1986). Sobre a música popular. In G. Cohn. (Org.), Theodor W. Adorno: Sociologia (F. R. Kothe, A. Onesti \& A. Cohn, trad., pp.115-146). São Paulo: Ática. (Trabalho original publicado em 1941)

Benjamin, W. (1989). Sobre alguns temas em Baudelaire. In W. Benjamin, Charles Baudelaire: Um lírico no ange do capitalismo. (J. M. Barbosa \& H. A. Baptista, trad., pp. 103-149). São Paulo: Brasiliense. (Trabalho original publicado em 1939)

Freud, S. (1975). O ego e o id. In S. Freud, Pequena coleção das obras de Freud (J. O. de A. Abreu, trad.). Rio de Janeiro: Imago. (Trabalho original publicado em 1923) . (1986). El mal estar en la cultura.

In N.A. Braustein (Org.) A medio siglo de el mal estar en la cultura de Sigmund Freud. (J. L. Etcheverry, trad., pp. 13-116) México: Siglo Veintiuno. (Trabalho original publicado em 1930)

. (1993a). Más allá del principio de

placer. In S. Freud, Obras Completas de Sigmund Freud (J. L. Etcheverry, trad., vol.18, pp. 1-62). Buenos Aires: Amorrortu. (Trabalho original publicado em 1920)

. (1993b). Psicología de las masas y análisis del yo. In S. Freud, Obras Completas de Sigmund Freud (J. L. Etcheverry, trad., vol.18, pp. 67-136). Buenos Aires: Amorrortu. (Trabalho original publicado em 1921) 
Horkheimer, M. (1976). A eclipse da razão. (S. U. Leite, trad.) Rio de Janeiro, RJ: Editorial Labor. (Trabalho original publicado em 1946)

\& Adorno, T. W. (1956). Ideologia. In M. Horkheimer \& T.W. Adorno. Temas básicos de sociologia. (A. Cabral, trad., pp. 184-205). São Paulo: Cultrix.

. (1985). Dialética do esclarecimento. (G. A. de Almeida, trad.). Rio de Janeiro: Jorge Zahar. (Trabalho original publicado em 1947)

Kant, I. (1991). Crítica da razão pura. In Coleção: Os Pensadores (V. Rohden \& U. B. Moosburger, trad.). São Paulo: Nova Cultural. (Trabalho original publicado em 1781)

Laplanche, J. \& Pontalis, J-B. (1988). Vocabulário da psicanálise (P. Tamen, trad., 10a ed.). São Paulo: Martins Fontes.

Marcuse, H. (1981). Eros e civilização. (A. Cabral, trad.). Rio de Janeiro: Zahar. (Trabalho original publicado em 1955)

(1998). Industrialização e capitalismo na obra de Max Weber. In H. Marcuse, Cultura e sociedade. Vol. II. (W. L. Maar, I. M. Loureiro \& R. de Oliveira, trad., pp. 113-136). Rio de Janeiro: Paz e Terra. (Trabalho original publicado em 1964)

Marx, K. (1984). O capital: Crítica da economia politica (R. Sant'Anna, trad., 9a ed., vol. 1). São Paulo: Difel. (Trabalho original publicado em 1867)

Marx, K. \& Engels, F. (1987). A ideologia alemã (Feuerbach) (J. C. Bruni \& M. A. Nogueira, trad., 6a ed.). São Paulo: Hucitec. (Trabalho original publicado em 1847)

Matos, O. C. F de. (1993). Iluminismo visionário: Benjamin, leitor de Descartes e Kant. São Paulo: Brasiliense.

Rouanet, S. P. (1985). A razão cativa. São Paulo: Brasiliense.

\section{NOTAS}

${ }^{1}$ Essa tese é também defendida por Rouanet (1985) em seu livro Raz̃ão cativa.
2 Sobre essa questão, consultar Matos (1993).

${ }^{3}$ Horkheimer e Adorno (1947/1985) dizemnos que no sonho nos sentimos felizes, uma vez que podemos esquecer quem somos; o mesmo vale, em alguma medida, para os antigos bacanais e para o carnaval, quando este último retinha alguma espontaneidade.

${ }^{4}$ Não se deve exagerar essa distinção entre ambos os tipos de amor, posto que, mesmo no amor anaclítico, os objetos que lhe servem de base devem representar situações prazerosas vividas outrora. Nas palavras de Laplanche e Pontalis (1988): "Mas é duvidoso que se possa opor, mesmo como tipos ideais, escolha narcísica e escolha anaclítica. E no 'pleno amor de objecto segundo o tipo anaclítico' que Freud encontra a 'hipervaloração sexual impressionante que tem justamente a sua origem no narcisismo originário da criança, e corresponde pois a uma transferência deste narcisismo para o objecto sexual" (p. 211). Apesar disso, devemos ressaltar que Freud (1921/1993b) insistiu em que somente o amor ao objeto combate o narcisismo.

5 “A racionalização privada, o auto-engano do espírito subjetivo, não é o mesmo que a ideologia, não é a falsidade do espírito objetivo. Não obstante, os mecanismos de defesa do indivíduo voltam uma ou outra vez a buscar reforços nos da sociedade, já estabelecidos e acreditados muito mais vezes."

6 "Pelos trabalhos realizados no Instituto de Investigações Sociais, que lamentavelmente não temos podido desenvolver o suficiente, temos alguns indícios de que se produz uma curiosa dualidade. Por um lado, os indivíduos são obedientes aos mecanismos de personalização, tal como são exercidos pela indústria da cultura (recordo os papéis de Soraya e Beatriz); mas, por outro lado, se alguém escarva só um pouco( e não necessita nenhum ' questionário profundo' para isso; pode-se comprovar facilmente), se acautela que os indivíduos sabem, realmente, que o importante não passa pela princesa Beatriz e pela senhora Soraya, ou quem seja."

jlchna@usp.br

Recebido em março/ 2007. Aceito em junbo/2007. 